\title{
Infusion Procedure
}

National Cancer Institute

\section{Source}

National Cancer Institute. Infusion Procedure. NCI Thesaurus. Code C15388.

Any form of treatment that is introduced into the body via a blood vessel, a muscle, or the spinal cord. 